Check for updates

Cite this: Chem. Commun., 2021, 57,9244

Received 30th June 2021, Accepted 26th July 2021

DOI: $10.1039 / \mathrm{d} 1 \mathrm{cc} 03514 \mathrm{~b}$

rsc.li/chemcomm

\section{Enantioselective vinylogous-Mukaiyama-type dearomatisation by anion-binding catalysis $\dagger$}

\author{
Kirandeep Kaur, $\ddagger^{\mathrm{a}}$ Jorge Humbrias-Martín, $\ddagger^{\mathrm{b}}$ Leon Hoppmann, ${ }^{a}$ \\ Jose A. Fernández-Salas, (D) ${ }^{\text {bc }}$ Constantin G. Daniliuc, ${ }^{a}$ José Alemán (D) ${ }^{b c}$ and \\ Olga García Mancheño (D) *a
}

The first enantioselective vinylogous Mukaiyama-type dearomatisation of heteroarenes under anion-binding catalysis is presented. A recyclable tetrakistriazole catalyst was used for the enantiocontrol of the remote vinylogous active position of silyl dienol ethers. This approach provided chiral heterocycles bearing $\alpha, \beta$-unsaturated chains with complete regioselectivity and excellent enantioselectivities (up to $97.5: 2.5$ e.r.).

Asymmetric vinylogous-Mukaiyama reactions have become a powerful tool for the generation of multifunctional chiral scaffolds commonly occurring in natural products bearing easily derivatisable unsaturated carbon chains, which allow the construction of more complex structures. ${ }^{1}$ Based on Fuson's principle of vinylogy, ${ }^{2}$ the incorporation of an additional adjacent double bond to silyl enol ethers extends and strengthens their nucleophilicity at the $\gamma$-position, which provides a different, appealing connectivity in the products. As a result, several enantioselective approaches for vinylogous Mukaiyama-type reactions have been developed with silyl dienolates. ${ }^{1}$ Among them, multiple organocatalytic systems based on different activation modes, including hydrogen-bonding, Lewis-base and ion-pairing catalysis, have been described (eqn (A), Scheme 1). ${ }^{3}$ However, vinylogous Mukaiyama reactions under anion-binding organocatalysis ${ }^{4}$ has long been prevented, most probably as a consequence of the longrange enantioinduction that the silyl dienolate would require. ${ }^{5}$

\footnotetext{
${ }^{a}$ Organic Chemistry Institute, University of Münster, 48149 Münster, Germany. E-mail: olga.garcia@uni-muenster.de

${ }^{b}$ Organic Chemistry Department (Module 1), Facultad de Ciencias, Universidad Autónoma de Madrid, 28049 - Madrid, Spain. E-mail: jose.aleman@uam.es; Web: www.uam.es/jose.aleman

${ }^{c}$ Institute for Advanced Research in Chemical Sciences (IAdChem), Universidad Autónoma de Madrid, 28049 - Madrid, Spain

$\dagger$ Electronic supplementary information (ESI) available: Synthetic procedures, analytical data of new compounds, SFC and HPLC chromatograms, kinetics, X-ray analysis of $\mathbf{4 k}$ and NMR collection (PDF). CCDC 2069596. For ESI and crystallographic data in CIF or other electronic format see DOI: $10.1039 / \mathrm{d} 1 \mathrm{cc03514b}$

$\$$ These authors contributed equally to this work.
}

Inspired by the power of dearomatisation methods ${ }^{6}$ and the anion-binding catalysed asymmetric functionalisation of activated $\mathrm{N}$-heteroarenes such as (iso)quinolines and pyridines by nucleophilic addition, ${ }^{4,7,8}$ we tackled this deficiency in the vinylogous-Mukaiyama technology. To the best of our knowledge, the use of silyl dienol ether derivatives as vinylogous nucleophiles in this type of asymmetric dearomatisation process has never been accomplished. This approach will allow straightforward access to highly functionalised enantiopure $\mathrm{N}$-heterocyclic derivatives, which are abundant structural motifs in high demand for drug discovery processes, ${ }^{9-11}$ in a single operation from readily available heteroaromatic platforms. ${ }^{12}$

Based on previous studies, ${ }^{8 d, 13}$ we envisioned that multidentate foldameric triazole-based catalysts, able to form a chiral contact ion-pair by recognition of the counterion of the in situ generated $\mathrm{N}$-acyl salt as well as bridge both the cationic substrate and nucleophile, would be an excellent platform to test this vinylogous reaction. Hence, in this work, we present the asymmetric dearomatisation of heteroarenes such as quinazolines with silyl dienol ethers, enabling the first vinylogous
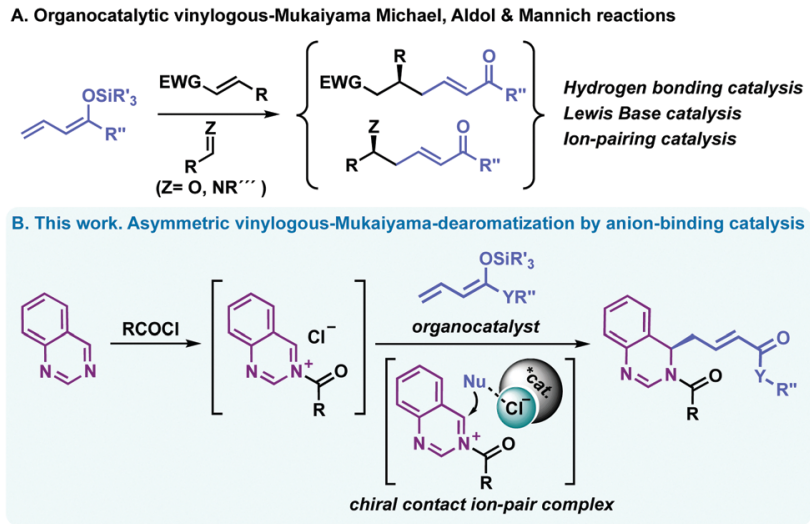

Scheme 1 Previous organocatalytic vinylogous Mukaiyama strategies (eqn (A)) and the present work (eqn (B)). 
Mukaiyama, Mannich-type dearomatization reaction under anion-binding catalysis (eqn (B), Scheme 1).

We began our investigations by studying the reaction of quinazoline (2a) as the model substrate with tert-butyldimethylsilyl (TBS)-substituted methylcrotonate nucleophile 3a (Table 1, see the ESI $\dagger$ for full screening). The reaction was performed in the presence of different hydrogen-bond (HB) donor organocatalysts $\mathbf{1}$ and 2,2,2-trichloroethoxycarbonyl chloride (TrocCl) as the acylating agent for the in situ formation of the quinazolinium salt. At first, all catalysts were examined in MTBE at $-78{ }^{\circ} \mathrm{C}$ (entries $1-5$ ), as a strong uncatalysed background reaction to form a regioisomeric mixture of the vinylogous products $\mathbf{4 a}$ and $\mathbf{4} \mathbf{a}^{\prime}$ was always observed (1.7:1 ratio, entry 6). ${ }^{14}$ Interestingly, catalytic reactions with the HB-donors $\mathbf{1}$ only delivered the C4-addition product $\mathbf{4 a}$. The tetrakistriazoles $1 \mathbf{a}$ and $\mathbf{1 b}$ showed superior efficiency regarding both yield and enantioselectivity (entries 1 and 2), while the more powerful HB-donor bisthiourea 1e displayed almost no stereocontrol (entry 5). After selecting 1a as the optimal catalyst, the catalytic loading was considered (entries 7 and 8), the best enantioselectivity was shown when employing $3 \mathrm{~mol} \%$ of $\mathbf{1 a}$ (entry 7 ). Finally, changing the solvent to toluene led to the 3 , 4-dihydroquinazoline $\mathbf{4 a}$ in an enhanced excellent enantioselectivity of $95.5: 4.5$ e.r. (entry 10).

Table 1 Optimisation of the Mukaiyama-dearomatisation ${ }^{a}$
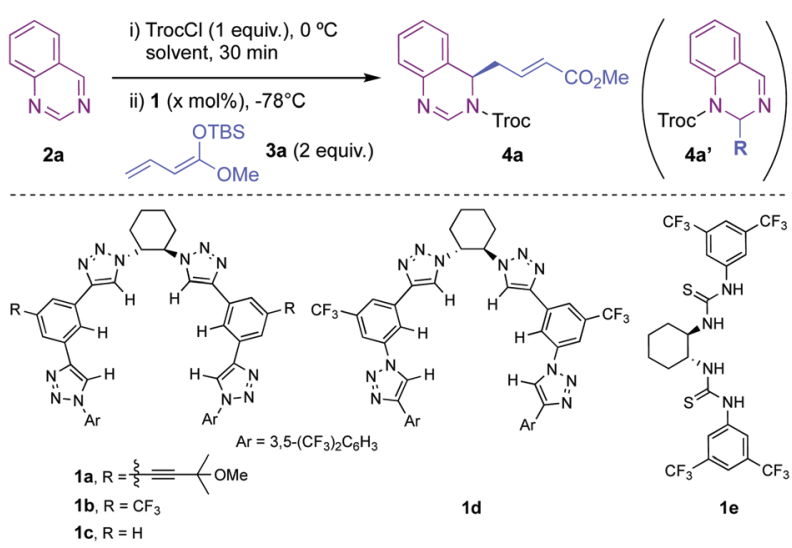

\begin{tabular}{|c|c|c|c|c|c|}
\hline Entry & Cat. (mol\%) & Solvent & $\mathbf{4 a} / \mathbf{4} \mathbf{a}^{\prime b}$ & Yield $\mathbf{4} \mathbf{a}^{c}(\%)$ & e.r. ${ }^{d}$ \\
\hline 1 & $1 \mathbf{a}(10)$ & MTBE & $>25: 1$ & 69 & $84: 16$ \\
\hline 2 & $\mathbf{1 b}(10)$ & MTBE & $>25: 1$ & 69 & $82: 18$ \\
\hline 3 & $1 c(10)$ & MTBE & $>25: 1$ & 46 & $77: 23$ \\
\hline 4 & 1d (10) & MTBE & $>25: 1$ & 58 & $75: 25$ \\
\hline 5 & 1e (10) & MTBE & $>25: 1$ & 48 & $52: 48$ \\
\hline 6 & - & MTBE & $1.7: 1$ & $49^{e}$ & - \\
\hline 7 & $1 \mathbf{a}(3)$ & MTBE & $>25: 1$ & 73 & $90: 10$ \\
\hline 8 & $1 \mathrm{a}(1)$ & MTBE & $>25: 1$ & 63 & $88: 12$ \\
\hline 9 & $1 \mathrm{a}(3)$ & $\mathrm{Et}_{2} \mathrm{O}$ & $>25: 1$ & 54 & $87: 13$ \\
\hline 10 & $1 \mathrm{a}(3)$ & Toluene & $>25: 1$ & 57 & $95.5: 4.5$ \\
\hline
\end{tabular}

${ }^{a}$ Conditions: (i) $2 \mathrm{a}(0.1 \mathrm{mmol}, 1$ equiv.) and TrocCl (1 equiv.) in the appropriate solvent at $0{ }^{\circ} \mathrm{C}, 30 \mathrm{~min}$; (ii) at $-78{ }^{\circ} \mathrm{C}$, catalyst $\mathbf{1}(x \mathrm{~mol} \%)$ and 3a ( 2 equiv.) were added and the reaction was stirred for $18 \mathrm{~h}$. ${ }^{b} \mathbf{4 a} / \mathbf{4 a} \mathbf{a}^{\prime}$ ratio determined using ${ }^{1} \mathrm{H}$ NMR of the reaction mixture. ${ }^{c}$ Yield of the isolated product. ${ }^{d}$ The enantiomeric ratios (e.r.) were measured using chiral-phase SFC. ${ }^{e}$ In the uncatalysed reaction, 4a was formed in $31 \%$ yield and the $\mathrm{C} 2$-addition regioisomer $\mathbf{4} \mathbf{a}^{\prime}$ in $18 \%$ yield (see the ESI).
With the optimised conditions in hand (entry 10, Table 1), the scope of the reaction was studied (Table 2). Different silyldienol derivatives were initially tested (Table 2, top). While the tert-butyl and phenyl dienol ethers performed very efficiently, giving rise to the desired products (4b and $\mathbf{4 c}$ ) in excellent

Table 2 Scope of the enantioselective Mukaiyama-type reaction ${ }^{a}{ }^{c}$
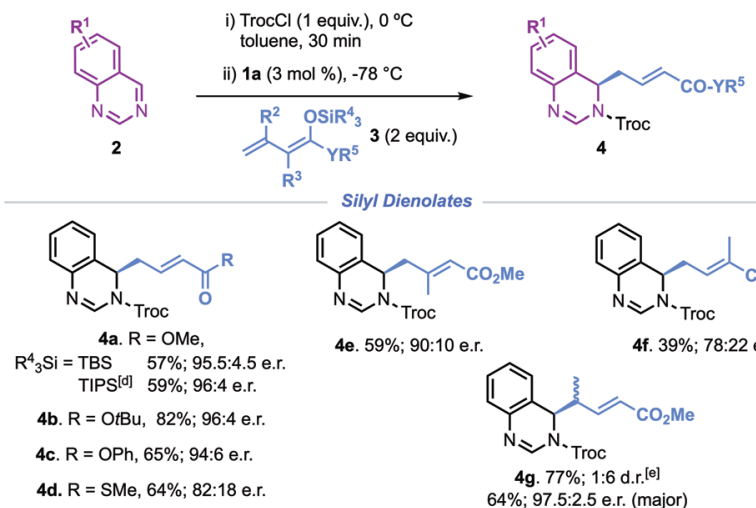

4e. 59\%; 90:10 e.r.

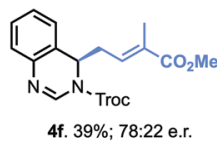

4d. $\mathrm{R}=\mathrm{SMe}, 64 \% ; 82: 18$ e.r.

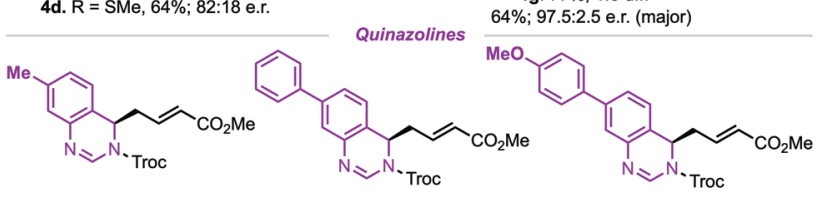

4h. $65 \% ; 95: 5: 4.5$ e.r. 4i. $96 \%$; $94: 6$ e.r. 4j. 99\%; 95:5 e.r.
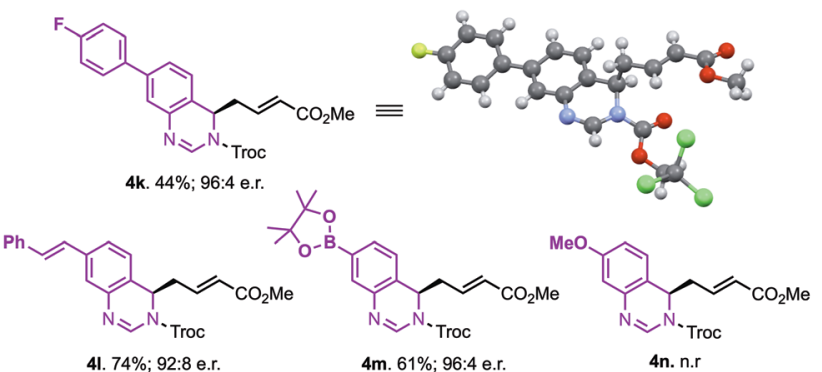

4l. $74 \% ; 92: 8$ e.r. 4m. $61 \%$; $96: 4$ e.r.

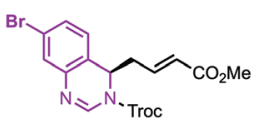

4o. $79 \% ; 94: 6$ e.r.
58\%; $97: 3$ e.r.

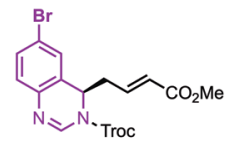

4p. $75 \% ; 80: 20$ e.r.
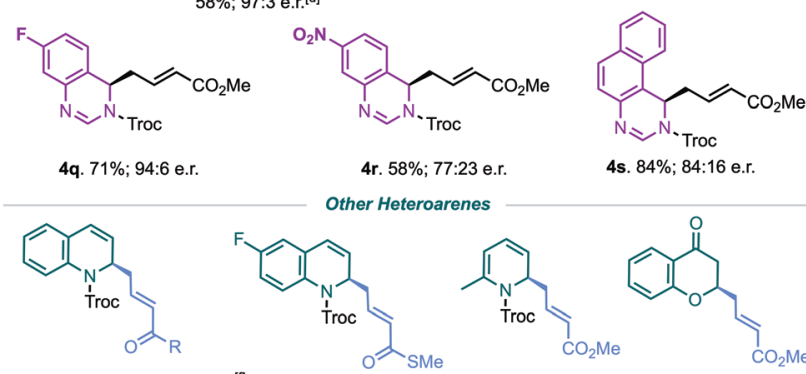

4s. $84 \% ; 84: 16$ e.r.

5a. $R=$ OMe, $81 \% ; 82: 18$ e.r. [f] $^{[f]}$

${ }^{a}$ Reaction conditions: (i) 2 (0.1 mmol, 1.0 equiv.) and TrocCl (1.0 equiv.) in toluene $30 \mathrm{~min}$ at $0{ }^{\circ} \mathrm{C}$; (ii) after cooling down to $-78{ }^{\circ} \mathrm{C}, 1 \mathrm{a}(3 \mathrm{~mol} \%)$ and TBS-3 ( 2 equiv.) were added and the reaction was stirred for $18-24 \mathrm{~h} .{ }^{b}$ Yields of the isolated products. ${ }^{c}$ Enantiomeric ratios determined using chiral-phase SFC. ${ }^{d}$ Reaction performed with TIPS-dienolate $3 \mathbf{b}$. ${ }^{e}$ Determined using ${ }^{1}$ HNMR. ${ }^{f}$ Reaction using 1d $(10 \mathrm{~mol} \%)$ in $\mathrm{Et}_{2} \mathrm{O}: \mathrm{C}_{6} \mathrm{~F}_{6}(3: 1)$ at $-30{ }^{\circ} \mathrm{C} .{ }^{g}$ Reaction using 1d $(10 \mathrm{~mol} \%)$ in $\mathrm{C}_{6} \mathrm{~F}_{6}$ at $6{ }^{\circ} \mathrm{C} .{ }^{h}$ Reaction using $1 \mathrm{a}(5 \mathrm{~mol} \%)$ in toluene at $-78{ }^{\circ} \mathrm{C}$. 
yields and enantioselectivities, a thioester substitution led to inferior enantiocontrol (4d). It should be highlighted that the more sterically hindered triisopropylsilyl (TIPS) substitution at the dienol derivative provided a slightly improved enantioselectivity, furnishing 4a in 96:4 e.r. Moreover, substitution on the diene-unit was also tolerated. The 2-methyl dienol 3e gave rise to the $\beta, \beta$-disubstituted product $4 \mathrm{e}$ in a $90: 10$ e.r., whereas substitution at the C-3 position led to a decrease in both the yield and the enantioselectivity (4f). Remarkably, the $\gamma$-methyl derivative built the product $\mathbf{4 g}$ as a $1: 6$ diasteromeric mixture and at an excellent $97.5: 2.5$ e.r. (major isomer).

Next, the scope of the quinazoline was examined (Table 2, middle). The method tolerated a variety of groups, proceeding remarkably smoothly with the 7-alkyl and aryl substituted quinazolines. Thus, the dearomatised products $\mathbf{4 h}$ and $\mathbf{4 i - k}$ were obtained with excellent enantiocontrol, no matter the electronic nature of the substituent. An olefin conjugated system or the versatile pinacolatoboron (Bpin) moiety were likewise well-suited, building the desired products $\mathbf{4 l}$ and $\mathbf{4 m}$ with excellent enantioselectivities. Unexpectedly, even when full conversion of 7-methoxyquinazoline into its stabilized $\mathrm{N}$-acyl iminium ion was observed, $4 \mathrm{n}$ was not formed and the starting quinazoline was mostly recovered after workup. Conversely, reaction with halogenated 7-bromo and 7-fluor quinazolines led to the corresponding substituted adducts $\mathbf{4 o}$ and $\mathbf{4 q}$ with very good enantioselectivities (up to $97: 3$ e.r.), while the nitro group showed significantly lower enantiocontrol (4r). Moreover, substitution at positions 6 (4p) and 5 (4s) was also compatible. Moreover, in order to extend the applicability of the method, other heteroarenes such as quinoline, pyridine and 4-chromenone ${ }^{15}$ derivatives were also enrolled (see the ESI $\dagger$ for more details), providing the corresponding products 5-7 in moderate to good enantioselectivities. The absolute configuration of the newly formed stereocentre was unequivocally assigned as $(R)$ using X-ray crystallographic analysis of the quinazoline product $\mathbf{4 k}$ (see Table 2 and the ESI $\dagger$ ). ${ }^{16}$ The same stereochemical outcome was assumed for all the compounds of this series.

To our delight, upscaling the model reaction of quinazoline (2a) 10 times $(1 \mathrm{mmol}$ vs. $0.1 \mathrm{mmol})$ led to a remarkable enhancement in the efficiency of the process (Scheme 2, top). In this case, the TIPS-dienolate $\mathbf{3 b}$ that led to the best enantioselectivity was employed, providing the desired product in a significantly higher yield ( $83 \%$ vs. 59\%), while no erosion of the enantioselectivity of the process was observed. In addition, to further prove the utility and applicability of the method, we showed the possibility of recovering the catalyst from the reaction mixture (in 90\% yield) and re-using it (Scheme 2, middle). Hence, a subsequent reaction with the recovered catalyst gave similar results in terms of both yield and enantioselectivity (see entry 10, Table 1 ). We next investigated the synthetic value of the obtained multifunctional chiral quinazoline derivatives with respect to the presence of the $\alpha, \beta$-unsaturated system introduced through the vinylogous addition. Thus, the $\mathrm{N}$-deprotection of $4 \mathrm{a}(0.5 \mathrm{mmol}, 96: 4$ e.r.) with $\mathrm{Zn}$ followed by selective hydrogenation of the conjugated double bond led to the

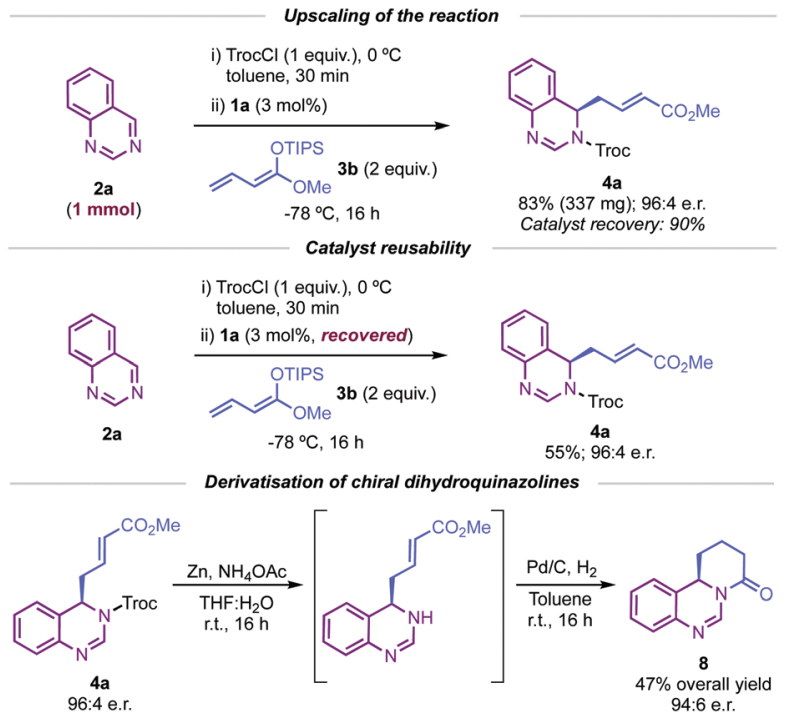

Scheme 2 Upscaling of the reaction, catalyst recovery/reusability and derivatisation towards ring-fused systems.

interesting chiral lactam derivative $\mathbf{8}$ after in situ cyclisation without significant erosion of the enantiopurity of the final product (Scheme 2, bottom).

Finally, evolving from earlier reports, ${ }^{4,13}$ a plausible mechanism that explains the observed enantioselectivity outcome of this vinylogous asymmetric anion-binding catalytic reaction is proposed (Scheme 3). After the in situ generation of the substrate of the reaction, the quinazolium salt I, upon treatment of quinazoline with TrocCl, a chiral contact ion pair II between catalyst $\mathbf{1 a}$ and $\mathbf{I}$ by anion-binding to its counteranion is formed. A plausible transition state (III) presenting multiple interactions of the chiral contact ion pair complex II with both reactants can then be envisioned. Thus, the cationic substrate I is fixed via coulomb attractions with the anionic 1a-Cl complex and $\pi-\pi$ stacking with one arm of the catalyst. In addition, the

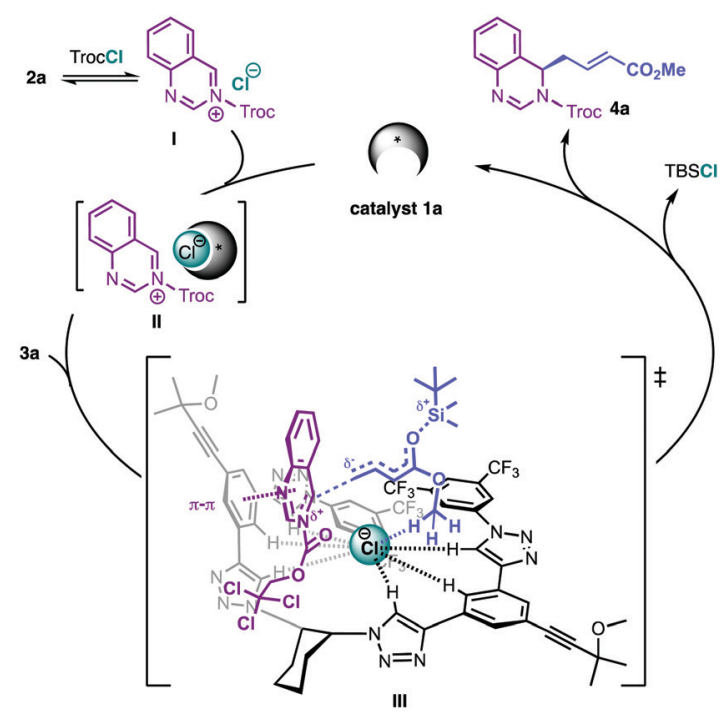

Scheme 3 Proposed mechanism. 
TBS-dienolate 3a shows hydrogen-bonding with the chloride counteranion, orientating its distal $\delta$-carbon towards the $\mathrm{C} 4$ position of the substrate ${ }^{17}$ and allowing for the selective vinylogous nucleophilic attack of the more accessible Re-face of the quinazolinium moiety. Hence, $(R)-\mathbf{4 a}$ is obtained as the major product, with concomitant formation of TBSCl.

In conclusion, we have described the first enantioselective organocatalysed vinylogous Mukaiyama-type reaction for the dearomatisation of heteroarenes under anion binding catalysis. The process takes place with high enantiocontrol (up to $97.5: 2.5$ e.r.) and with a range of differently substituted quinazolines, which could be extended to other types of $\mathrm{N}$ - and O-heterocycles. In addition, different experiments and studies such as catalyst recovery/reusability and the derivatisation of the final products have been performed in order to further illustrate the utility and applicability of the presented method.

The European Research Council (ERC-CoG-FRICatANIONS, No. 724695; ERCCoG-UNBICAT, No. 647550) and the Deutsche Forschungsgemeinschaft (DFG) within the SFB858 are gratefully acknowledged for generous support. We are also grateful to the Spanish Government (RTI2018-095038-B-I00) and the "Comunidad de Madrid" and European Structural Funds (S2018/NMT-4367). J. A. F.-S. thanks the Spanish Government for a Ramón y Cajal Contract.

\section{Conflicts of interest}

There are no conflicts to declare.

\section{Notes and references}

1 (a) M. Kalesse and J. Hassfeld, in Asymmetric Synthesis-The Essentials, ed. M. Christmann and S. Bräse, Wiley-VCH, Weinheim, 2008, 2nd edn, pp. 112-116. See also; $(b)$ Y. Kim, R. A. Singer and E. M. Carreira, Angew. Chem., Int. Ed., 1998, 37, 1261-1263; (c) M. Christmann, U. Bhatt, M. Quitschalle, E. Claus and M. Kalesse, Angew. Chem., Int. Ed., 2000, 39, 4364-4366; (d) D. A. Evans, D. M. Fitch, T. E. Smith and V. J. Cee, J. Am. Chem. Soc., 2000, 122, 10033-10046; (e) J. Hassfeld, M. Christmann and M. Kalesse, Org. Lett., 2001, 3, 3561-3564; $(f)$ J. Hassfeld and M. Kalesse, Synlett, 2002, 2007-2010; $(g)$ I. Paterson, R. D. M. Davies, A. C. Heimann, R. Marquez and A. Meyer, Org. Lett., 2003, 5, 4477-4480; (h) F. Liesener and M. Kalesse, Synlett, 2005, 2236-2238; (i) S. E. Denmark and S. Fujimori, J. Am. Chem. Soc., 2005, 127, 8971-8973; $(j)$ E. H. Sessions and P. A. Jacobi, Org. Lett., 2006, 8, 4125-4128; ( $k$ ) M. Yamaoka, Y. Fukatsu, A. Nakazaki and S. Kobayashi, Tetrahedron Lett., 2009, 50, 3849-3852.

2 R. C. Fuson, Chem. Rev., 1935, 16, 1-27.

3 (a) M. Frías, W. Cieslik, A. Fraile, A. Rosado-Abón, A. F. GarridoCastro, F. Yuste and J. Alemán, Chem. - Eur. J., 2018, 24, 10906-10933; (b) C. Curti, L. Battistini, A. Sartori and F. Zanardi, Chem. Rev., 2020, 120, 2448-2612. Selected vinylogous Mannich-type examples: $(c)$ M. Sickert and C. Schneider, Angew. Chem., Int. Ed., 2008, 47, 3631-3634; (d) D. S. Giera, M. Sickert and C. Schneider, Org. Lett., 2008, 10, 4259-4262; (e) M. Sickert, F. Abels, M. Lang, J. Sieler, C. Birkemeyer and C. Schneider, Chem. - Eur. J., 2010, 16, 2806-2818; $(f)$ Q. Wang, M. van Gemmeren and B. List, Angew. Chem., Int. Ed., 2014, 53, 13592-13595.

4 Selected reviews: $(a)$ Z. Zhang and P. R. Schreiner, Chem. Soc. Rev., 2009, 38, 1187-1198; (b) R. J. Phipps, G. L. Hamilton and F. D. Toste, Nat. Chem., 2012, 4, 603-614; (c) S. Beckendorf, S. Asmus and
O. García Mancheño, ChemCatChem, 2012, 4, 926-936; (d) M. Mahlau and B. List, Angew. Chem., Int. Ed., 2013, 52, 518-533; (e) K. Brak and E. N. Jacobsen, Angew. Chem., Int. Ed., 2013, 52, 534-561; $(f)$ D. Seidel, Synlett, 2014, 783-794; $(\mathrm{g})$ M. D. Visco, J. Attard, Y. Guan and A. E. Mattson, Tetrahedron Lett., 2017, 58, 2623-2684.

5 Example of vinylogous addition to allenoates: V. Kumar and S. Mukherjee, Chem. Commun., 2013, 49, 11203-11205.

6 Selected reviews: (a) C. Tsukano and Y. Takemoto, Dearomatisation Reactions of Electron-Deficient Aromatic Rings in Asymmetric Dearomatisation Reactions, ed. S.-L. You, Wiley-VCH, 2016, pp. 247-278; (b) J. A. Bull, J. J. Mousseau, G. Pelletier and A. B. Charette, Chem. Rev., 2012, 112, 2642-2713. For selected examples, see: (c) M. Takamura, K. Funabashi, M. Kanai and M. Shibasaki, J. Am. Chem. Soc., 2000, 122, 6327-6328; (d) K. Funabashi, H. Ratni, M. Kanai and M. Shibasaki, J. Am. Chem. Soc., 2001, 123, 10784-10785; (e) E. Ichikawa, M. Suzuki, K. Yabu, M. Albert, M. Kanai and M. Shibasaki, J. Am. Chem. Soc., 2004, 126, 11808-11809.

7 Pioneering work: M. S. Taylor, N. Tokunaga and E. N. Jacobsen, Angew. Chem., Int. Ed., 2005, 44, 6700-6704.

8 Selected examples: $(a)$ Y. Yamaoka, H. Miyabe and Y. Takemoto, J. Am. Chem. Soc., 2007, 129, 6686-6687; (b) C. K. De, N. Mittal and D. Seidel, J. Am. Chem. Soc., 2011, 133, 16802-16805; (c) A. G. Schafer, J. M. Wieting, T. J. Fisher and A. E. Mattson, Angew. Chem., Int. Ed., 2013, 52, 11321-11324; (d) M. Zurro, S. Asmus, S. Beckendorf, C. Mück-Lichtenfeld and O. García Mancheño, J. Am. Chem. Soc., 2014, 136, 13999-14002; (e) O. García Mancheño, S. Asmus, M. Zurro and T. Fischer, Angew. Chem., Int. $E d ., 2015$, 54, 8823-8827; $(f)$ A. R. Choudhury and S. Mukherjee, Chem. Sci., 2016, 7, 6940-6945; (g) J. Wen, R. Tan, S. Liu, Q. Zhao and X. Zhang, Chem. Sci., 2016, 7, 3047-3051; $(h)$ T. Fischer, Q.-N. Duong and O. García Mancheño, Chem. - Eur. J., 2017, 23, 5983-5987; (i) M. Gómez-Martínez, M. C. Pérez-Aguilar, D. G. Piekarski, C. G. Daniliuc and O. García Mancheño, Angew. Chem., Int. Ed., 2021, 60, 5102-5107.

9 (a) E. C. Taylor and J. E. Saxton, The Chemistry of Heterocyclic Compounds, Wiley-Interscience, New York, 1983/1994; (b) J. A. Joule and K. Mills, Heterocyclic Chemistry, Blackwell Science, Oxford, 2000; $(c)$ T. Eicher, S. Hauptmann and A. Speicher, The Chemistry of Heterocycles, Wiley-VCH Verlag GmbH \& Co, Weinheim, 2nd edn, 2003; (d) N. Saracoglu, Top. Heterocycl. Chem., 2007, 11, 145-178.

10 M. M. Heravi and V. Zadsirjan, RSC Adv., 2020, 10, 44247-44311.

11 Asymmetric Synthesis of Nitrogen Heterocycles, ed. J. Royer, Wiley-VCH Verlag, Weinheim, 2009.

12 (a) Q. Ding, X. Zhou and R. Fan, Org. Biomol. Chem., 2014, 12, 4807-4815; (b) A. M. M. M. Faisca Phillips,Organocatalytic Enantioselective Dearomatisation Reactions for the Synthesis of Nitrogen Heterocycles In Synthetic Approaches to Nonaromatic Nitrogen Heterocycles, ed. A. M. M. M. Faisca Phillips, Wiley-VCH, 2020, pp. 273-323; (c) C. Zhuo, W. Zhang and S. You, Angew. Chem., Int. Ed., 2012, 51, 12662-12686; (d) C. Zheng and S.-L. You, ACS Cent. Sci., 2021, 7, 432-444.

13 D. G. Piekarski, P. Steinforth, M. Gómez-Martínez, J. Bamberger, F. Ostler, M. Schönhoff and O. García Mancheño, Chem. - Eur. J., 2020, 26, 17598-17603.

14 The catalyst provokes a notable reaction acceleration, reaching completion after only $1 \mathrm{~h}$ (see the ESI $\dagger$ for details).

15 (a) A. M. Hardman-Baldwin, M. D. Visco, J. M. Wieting, C. Stern, S.-i. Kondo and A. E. Mattson, Org. Lett., 2016, 18, 3766; (b) T. Fischer, J. Bamberger, M. Gómez-Martínez, D. G. Piekarski and O. García Mancheño, Angew. Chem., Int. Ed., 2019, 58, 3217-3221.

16 The crystallographic data of $\mathbf{4 k}$ (CCDC 2069596†).

17 This pre-orientation seems crucial for achieving the observed selectivity towards 4a, suggesting a less efficient ion-pair recognition and reaction of the other possible $1 \mathrm{~N}$-Troc salt. 